\title{
High mechanical properties of rolled ZK60 Mg alloy through pre-equal channel angular pressing
}

\author{
Yuchun Yuan*, Aibin Ma**, Jinghua Jiang***, Xiaofan Gou****, Dan Song*****, \\ Donghui Yang*******, Weiwei Jian******** \\ *Hohai University, Nanjing 210098, China, E-mail: yychehai@163.com \\ **Hohai University, Nanjing 210098, China, E-mail: aibin-ma@hhu.edu.cn \\ ***Hohai University, Nanjing 210098, China, E-mail: jinghua-jiang@hhu.edu.cn \\ ****Hohai University, Nanjing 210098, China, E-mail:xfgou@hhu.edu.cn \\ *****Hohai University, Nanjing 210098, China, E-mail: songdancharls@hhu.edu.cn \\ ******Hohai University, Nanjing 210098, China, E-mail: yang_donghui76@hotmail.com \\ *******North Carolina State University, Raleigh, NC 27695, USA, E-mail: wjian@ncsu.edu \\ cross'ref http://dx.doi.org/10.5755/j01.mech.22.4.16161
}

\section{Introduction}

Magnesium alloy is considered as a promising structure material for its low density and high specific strength [1]. However, the hexagonal close-packed crystal structure of $\mathrm{Mg}$ alloy provides limited slip systems which usually results in poor ductility and formability at ambient temperature. In addition, because the critical resolved shear stresses(CRSS) of the basal slip is significantly lower than those of other slip systems and twinning mode at low temperature [2], strong deformation anisotropy generally develops during the forming process $[2,3]$ that directly affects its workability. Basal texture (the basal plan paralleled the rolling plane) usually formed during rolling [4, 5], which makes further rolling difficult and leads to poor ductility and inadequate strength of the rolled sheet. Therefore, how to avoid or weaken the rolling basal texture become important for improving the formability and mechanical property of the rolling magnesium alloy sheet. Differential speed rolling or rolling at high temperature could weaken the basal texture $[6,7]$, and thus improved the plasticity of the magnesium alloy sheets, but the strength still cannot be increased distinctly.

Equal channel angular pressing (ECAP) $[8,9]$ as a common severe plastic deformation (SPD) method could refine the grains of the magnesium alloy and improve its ductility notably $[10,11]$. The specific texture of ECAP $[3,10]$ played a great role in the good ductility and relatively low yield strength. Therefore, when ECAP was carried out before rolling, the fine microstructure and good ductility of the alloy would help for both of the rolling formability and mechanical properties.

\section{Experimental procedures}

The alloy used in this study was ZK60 with a composition of Mg-6.08wt\% Zn-0.56wt\% Zr. The ingot ZK60 alloy sample $(20 \mathrm{~mm} \times 20 \mathrm{~mm} \times 45 \mathrm{~mm})$ was first solution treated at $430^{\circ} \mathrm{C}$ for $16 \mathrm{~h}$ and ECAP processed (ECAPed) for 12 passes at $300^{\circ} \mathrm{C}$ by a rotational die ECAP setup [12]. Before rolling, the ECAPed sample was cut paralleling to the flow plane (X-Y shown in Fig. 1, a into $5 \mathrm{~mm}$ thick thin plates. Then these plates were rolled at room temperature $\left(\sim 25^{\circ} \mathrm{C}\right)$ and $150^{\circ} \mathrm{C}$. The plate was annealed at $380^{\circ} \mathrm{C}$ for
$0.5 \mathrm{~h}$ firstly to relax the residual strain before rolling at room temperature, and then rolled for multi passes until a total $30 \%$ reduction before fracture. When the plate was rolled at warm temperature, the plate was annealed at $300^{\circ} \mathrm{C}$ for 15 minutes before rolling, and between two rolling passes, it was re-annealed to $300^{\circ} \mathrm{C}$ for 5 minutes. The roller was kept at $150^{\circ} \mathrm{C}$ during the whole rolling process. The total rolling strain was up to $80 \%$ without cracks. For comparison, the solution treated ZK60 alloy was subjected to rolling alone at $150^{\circ} \mathrm{C}$ up to $40 \%$ rolling strain. Between two rolling passes, the plate was also annealed at $300^{\circ} \mathrm{C}$ for 5 minutes.

The microstructures of the ZK60 samples at different processing states were observed by optical microscopy (OM) and transmission electron microscopy (TEM). Aceticpicrate solution ( $3 \mathrm{~g}$ picric, $20 \mathrm{ml}$ acetic acid, $20 \mathrm{ml}$ water, and $50 \mathrm{ml}$ ethanol) was adopted for etching. The TEM specimens were prepared using jet polishing with a solution of $2 \%$ perchloric acid in ethanol at $-20^{\circ} \mathrm{C}$. Tensile tests were carried out at room temperature with a strain rate of $5 \times 10^{-}$ ${ }^{4} \mathrm{~s}^{-1}$. Dog-bone specimen as demonstrated in Fig. 1, a was used with the dimension of $1.0 \mathrm{~mm}$ thick, $2.0 \mathrm{~mm}$ wide and $6 \mathrm{~mm}$ in gage length. The texture evolution was explored by EBSD in the flow or rolling plane(X-Y), Fig. 1, a. In order to improve the surface quality, the EBSD samples were electro-polished in a 4:1 solution of ethanol and $\mathrm{H}_{3} \mathrm{PO}_{4}$ after mechanical polishing

\section{Results and discussion}

Fig. 1, a shows the process procedure at present study. The typical tensile stress-strain curves of the ZK60 samples at different processing states were exhibited in Fig. 1, b. Both of the strength and ductility of the rolled samples with pre-ECAP processing were higher than the rolled alone sample. The strengths were also much higher than the ECAPed sample. The combination of ECAP and cold rolling yielded the highest yield strength(YS) and ultimate strength(UTS), $396 \mathrm{MPa}$ and $430 \mathrm{Mpa}$, with $9.4 \%$ of the elongation to failure. The YS was up to two-fold of that of the ECAPed sample. When rolling at $150^{\circ} \mathrm{C}$, the rolling strain was up to $80 \%$ without any visible cracks, as the inset shown in Fig. 1, a, which was only $40 \%$ in the traditional warm rolling. Therefore, the good ductilit of the ECAPed alloy helped for improving the rolling formability at low 
temperature. Although the ductility of the rolled alloy decreased comparing to the ECAPed alone sample, both of the YS and UTS were enhanced significantly.

Pre-ECAP was demonstrated useful to enhance the rolling formability and mechanical properties of the ZK60 magnesium alloy. Fig. 2 shows the relevant microstructure evolution of the alloy with the operated processes. The solution treated ZK60 alloy had an equiaxed grain structure with the grain size of $\sim 200 \mu \mathrm{m}$. After rolling alone, the grains were refined to $\sim 18 \mu \mathrm{m}$. Because the rolling temperature was low, many twins could be seen inside the grains. The grains were refined to $\sim 7 \mu \mathrm{m}$ by ECAP. Due to the dynamic recrytallization, the twin density in the ECAPed alloy sample was lower than that in the rolled alone sample. When the sample was rolled at room temperature after ECAP, as shown in Fig. 2, d, the gains were further refined. Some su- perfine grains were hardly identified in the optical photograph. Through the TEM micrograph of the sample rolled at room temperature, Fig. 3, b, it could be seen clearly that the grains is finer than that of the ECAPed sample. The grains size was only $\sim 1 \mu \mathrm{m}$. Dynamic recrystallization happened during rolling even at room temperature. High density of dislocations could be seen in the ECAPed and rolled sample, Fig. 3, c. Twins could also be seen in some big grains in Fig. 2, d, but in the TEM micrograph Fig. 3, c, the twin density was not very high. The twin boundaries degraded and changed into subgrain/grain boundaries accompanying with the dynamic recrystallization. The superfine grain size improved the compatibility of deformation that helped for both of the strength and ductility. And the improved grain boundaries and dislocations undoubtedly improved the strength of the ECAPed and rolled alloy.
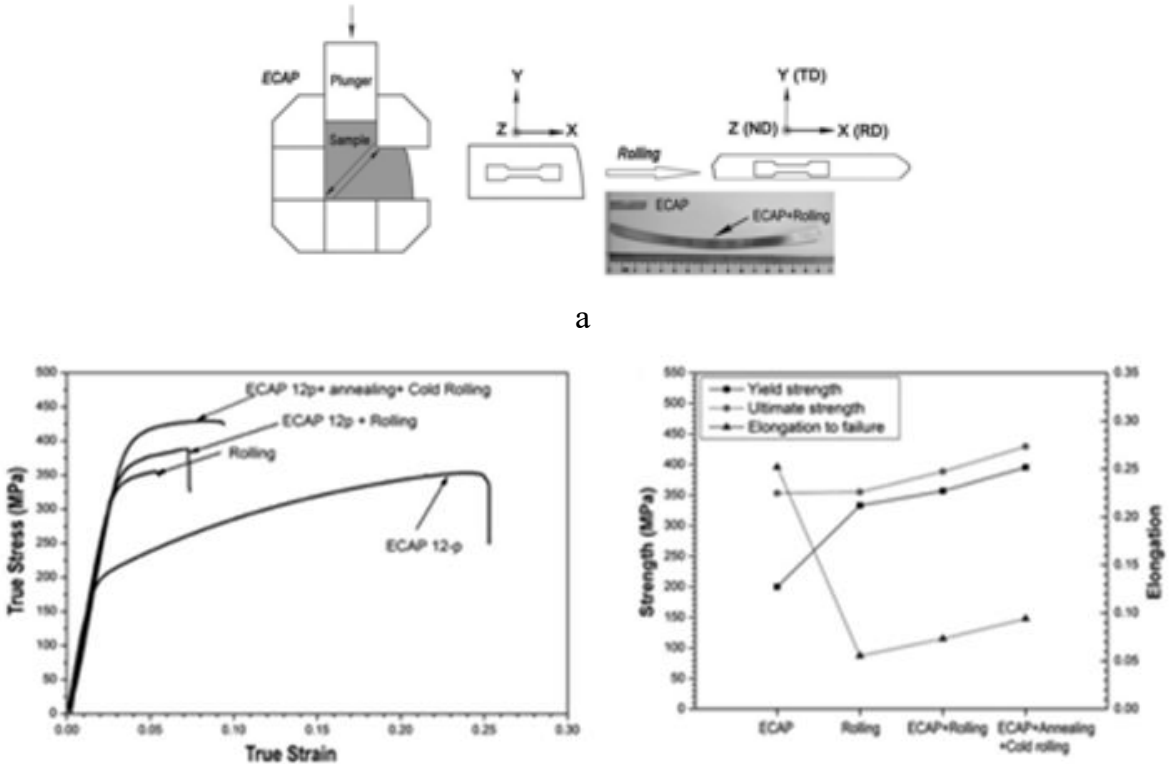

b

Fig. $1 \mathrm{a}$ - Schematic diagram of the ECAP and rolling processing; $\mathrm{b}$ - typical true stress-strain curves of ZK60 alloy samples at different processing state; and $\mathrm{c}$ - the comparison of the mechanical properties

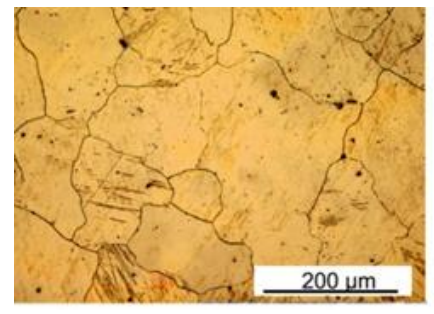

a

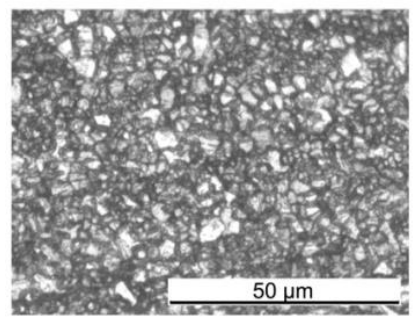

d

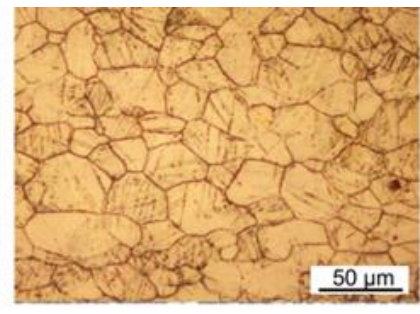

b

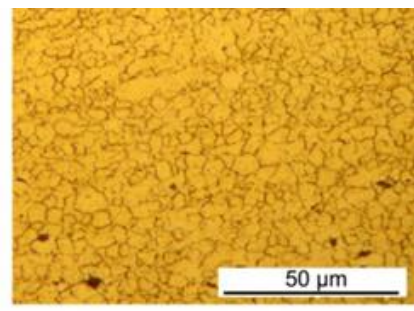

C

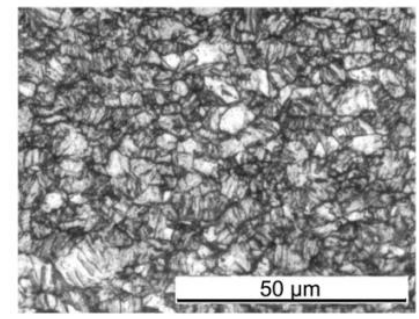

e

Fig. 2 Optical micrographs of a - the solution treated ZK60 and b - the traditional rolled alone sample, and the SEM image of the sample processed by c - ECAP; d - ECAP plus cold rolling $\left(25^{\circ} \mathrm{C}\right)$ and e - ECAP plus warm rolling $\left(150^{\circ} \mathrm{C}\right)$ 
When the ECAPed sample was rolled and annealed at higher temperature, $150^{\circ} \mathrm{C}$ and $300^{\circ} \mathrm{C}$ respectively, recrystallization took place and developed quickly. The average grain size was higher than that in the sample rolled at room temperature, as shown in Fig. 2, e. In addition, a large number of parallel twins could be seen inside the grains. Therefore, although the rolling strain was higher when rolling and annealing at higher temperature, the strength and ductility were lower.

Due to the great deformation anisotropy in magnesium alloys, the influence of the deformation texture in the mechanical properties cannot be ignored. The $\{0001\},\{10 \overline{1} 0\}$ pole figures and the inverse pole figures of the normal direction (ND) of the samples at different deformation state were studied by EBSD and exhibited in Fig. 3. The rolled alone sample showed a distinct but not very strong basal texture, as shown in Fig. 3, a. In addition to the basal texture, there was another preferred orientation that $<2 \overline{1} \overline{1} 1>$ nearly paralleled to the ND. Because the rolling temperature was only $150^{\circ} \mathrm{C}$, twinning as the dominated deformation mode to coordinate the dislocation slip partially changed the deformation texture. The $\{10 \overline{1} 2\}<\overline{1} 011>$ tension twinning and $\{10 \overline{1} 1\}<\overline{1} 012>$ compression twinning are the two most common twinning mechanisms in magnesium alloy [13]. When rolling at low temperature, once the basal texture formed, the tension twinning was hard to happen due to most of the grains are subjected to compression in the $\mathrm{c}$ axis. However, compression twinning was more stabilized and harder to migrate than the tension twinning [14].Therefore, the ductility and formability of the rolled alone sample was very poor.

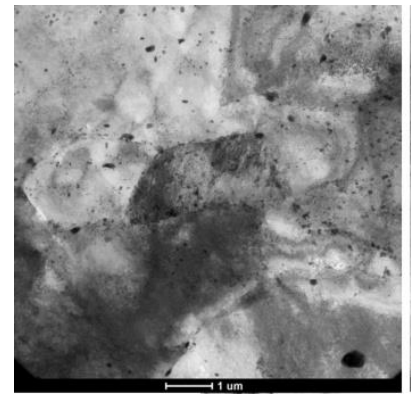

a

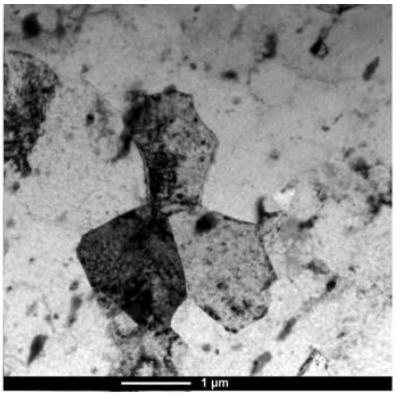

b

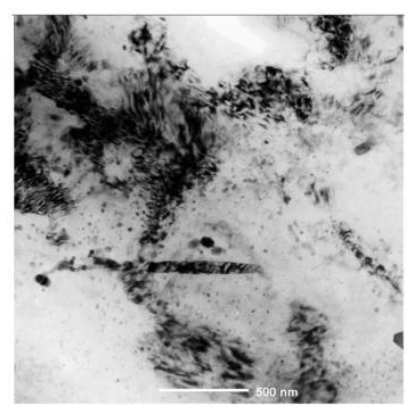

C

Fig. 3 TEM micrographs of a - the ZK60 alloy processed by ECAP; and $\mathrm{b}$ - the ZK60 alloy processed by ECAP and rolling at room temperature with the fine grains, $\mathrm{c}$ - dislocation tangles and twin

After ECAP processing, the basal planes in most grains preferred to incline to the ND and RD with an angle, as shown in Fig. 4, b, and $<2 \overline{1} \overline{1} 1>$ close to paralleled to ND. By subsequent rolling at room temperature with $30 \%$ reduction, a large number of dislocations and twins could be activated easily due to the favorable initial texture. Some of the basal planes rotated to parallel to the rolling direction, and the basal pole paralleled to the TD. Only a few of the basal plans rotated toward the rolling plane. The basal texture formation was impeded by the initial ECAP-texture. When rolling was conducted with a higher strain $(80 \%)$ at $150^{\circ} \mathrm{C}$, the texture trended to change in two ways. Some of the basal planes rotated $\sim 60^{\circ}$ to be symmetrically distributed to the initial texture, and some basal planes rotated toward the rolling plan. More twins were activated by the large compact deformation in the thickness. However, even by the $80 \%$ rolling strain, the maximum pole density of $\{0001\}$ was much lower than that of the rolled alone sample. The texture change accompanying with the big grains and high density of deformation defects led to the lower strength and ductility.
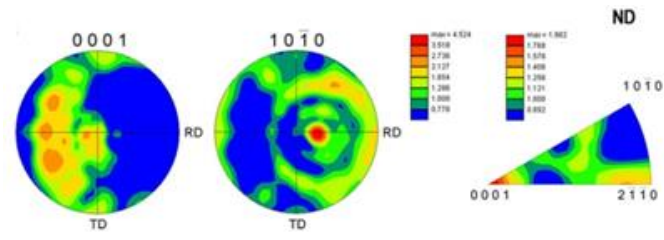

a
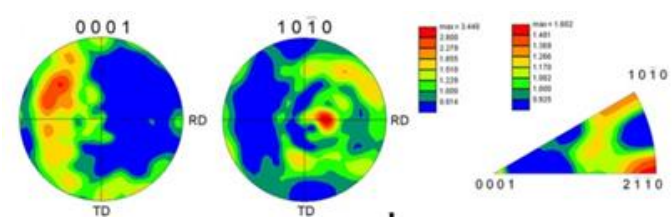

b


c
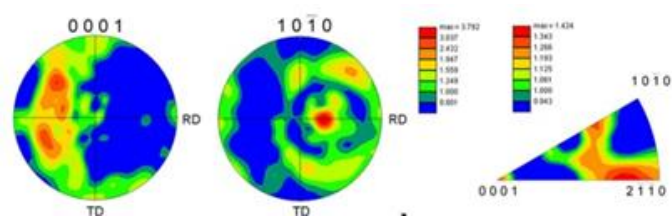

d

Fig. 4 Pole figures and the inverse pole figures show the crystallographic textures in: a - rolling; b-ECAP; $\mathrm{c}-\mathrm{ECAP}$ plus rolling at room temperature and $\mathrm{d}$ - ECAP plus warm rolling $\left(150^{\circ} \mathrm{C}\right)$ processed $\mathrm{ZK} 60$ samples determined by EBSD

\section{Conclusions}

Enhanced mechanical properties have been achieved in the rolled ZK60 Mg alloy sheet by pre-ECAP processing. The fine microstructure and specific texture of the ECAPed alloy led to the good rolling formability of the ZK60 Mg alloy at low temperature. During the subsequent 
rolling, the grains was further refined and the dislocations increased, which effectively improved the work hardening and the strength. The fine microstructure and non-basal texture facilitated the good ductility.

\section{Acknowledgements}

This work is financially supported by National Natural Science Foundation of China (Grant No. 51141002), Natural Science Foundation of Jiangsu Province of China (Grant No. BK20131373), and Jiangsu Planned Projects for Postdoctoral Research Funds (Grant No. 1402009A).

\section{References}

1. Mordike, B.L.; Ebert, T. 2001. Magnesium: properties-applications-potential, Materials Science and Engineering: A 302(1): 37-45.

http://dx.doi.org/10.1016/S0921-5093(00)01351-4.

2. Agnew, S.; Duygulu, Ã. 2005. Plastic anisotropy and the role of non-basal slip in magnesium alloy AZ31B, International Journal Of Plasticity 21(6): 1161-1193. http://dx.doi.org/10.1016/j.ijplas.2004.05.018.

3. Kim, W.; Hong, S.; Kim, Y.; Min, S.; Jeong, H.; Lee, J. 2003. Texture development and its effect on mechanical properties of an AZ61 Mg alloy fabricated by equal channel angular pressing, Acta Materialia 51(11): 3293-3307. http://dx.doi.org/10.1016/S1359-6454(03)00161-7.

4. Prasad, Y.; Rao, K. 2008. Processing maps for hot deformation of rolled AZ31 magnesium alloy plate: anisotropy of hot workability, Materials Science and Engineering A 487(1): 316-327. http://dx.doi.org/10.1016/j.msea.2007.10.038.

5. Jian, W.; Cheng, G.; Xu, W.; Yuan, H.; Tsai, M.; Wang, Q.; Koch, C.; Zhu, Y.; Mathaudhu, S. 2013. Ultrastrong $\mathrm{Mg}$ alloy via nano-spaced stacking faults, Materials Research Letters 1(2): 61-66. http://dx.doi.org/10.1080/21663831.2013.765927.

6. Huang, X.; Suzuki, K.; Chino, Y.; Mabuchi, M. 2011. Improvement of stretch formability of $\mathrm{Mg}-3 \mathrm{Al}-1 \mathrm{Zn}$ alloy sheet by high temperature rolling at finishing pass, Journal Of Alloys and Compounds 509(28): 7579-7584. http://dx.doi.org/10.1016/j.jallcom.2011.04.132.

7. Huang, X.; Suzuki, K.; Watazu, A.; Shigematsu, I.; Saito, N. 2008. Mechanical properties of Mg-Al-Zn alloy with a tilted basal texture obtained by differential speed rolling, Materials Science and Engineering A 488(1-2): 214-220. http://dx.doi.org/10.1016/j.msea.2007.11.029.

8. Segal, V.M. 1995. Materials processing by simple shear, Materials Science and Engineering A, 197(2): 157-164. http://dx.doi.org/10.1016/0921-5093(95)09705-8.

9. Valiev, R.Z.; Langdon, T.G. 2006. Principles of equalchannel angular pressing as a processing tool for grain refinement, Progress In Materials Science 51(7): 881981.

http://dx.doi.org/10.1016/j.pmatsci.2006.02.003.

10. Agnew, S.; Horton, J.; Lillo, T.; Brown, D. 2004. Enhanced ductility in strongly textured magnesium produced by equal channel angular processing, Scripta Materialia 50(3): 377-381.

http://dx.doi.org/10.1016/j.scriptamat.2003.10.006.

11. Yuan, Y.; Ma, A.; Jiang, J.; Lu, F.; Jian, W.; Song, D.; Zhu, Y.T. 2013. Optimizing the strength and ductility of AZ91 Mg alloy by ECAP and subsequent aging, Materials Science and Engineering A 588(0): 329-334. http://dx.doi.org/10.1016/j.msea.2013.09.052.

12. Ma, A.; Nishida, Y.; Suzuki, K.; Shigematsu, I.; Saito, N. 2005. Characteristics of plastic deformation by rotary-die equal-channel angular pressing, Scripta Materialia 52(6): 433-437. http://dx.doi.org/10.1016/j.scriptamat.2004.11.014.

13. Staroselsky, A.; Anand, L. 2003. A constitutive model for hcp materials deforming by slip and twinning: application to magnesium alloy AZ31B, International Journal Of Plasticity 19(10): 1843-1864. http://dx.doi.org/10.1016/S0749-6419(03)00039-1.

14. Yang, P.; Yu, Y.; Chen, L.; Mao, W. 2004. Experimental determination and theoretical prediction of twin orientations in magnesium alloy AZ31, Scripta Materialia 50(8): 1163-1168.

http://dx.doi.org/10.1016/j.scriptamat.2004.01.013.

Yuchun Yuan, Aibin Ma, Jinghua Jiang, Xiaofan Gou, Dan Song, Donghui Yang, Weiwei Jian

HIGH MECHANICAL PROPERTIES OF ROLLED ZK60 MG ALLOY THROUGH PRE-EQUAL CHANNEL ANGULAR PRESSING

S u m m a r y

Enhanced mechanical properties were achieved in the rolled ZK60 Mg alloy sheet by pre-equal channel angular pressing (ECAP). Pre-ECAP fabricated fine microstructure and consequently led to a good ductility in the ZK60 alloy. During the subsequent rolling, the grains were further refined and more dislocations were activated inside the fine grains that effectively increased the work hardening and the strength of the alloy. The typical rolling basal texture was suppressed by the initial ECAP texture that helped for both of the rolling formability and ductility of the alloy.

Keywords: Magnesium alloy, ECAP, rolling, strength, texture.

Received September 15, 2015 Accepted July 04, 2016 